\title{
On positive solutions for some second-order three-point boundary value problems with convection term
}

\author{
Yongfang Wei ${ }^{1}$, Zhanbing Bai ${ }^{*}$ (D) and Sujing Sun ${ }^{1}$
}

\section{"Correspondence: \\ zhanbingbai@163.com \\ ${ }^{1}$ College of Mathematics and \\ System Science, Shandong \\ University of Science and \\ Technology, Qingdao, P.R. China}

\begin{abstract}
In this paper, a fixed point theorem in a cone and some inequalities of the associated Green's function are applied to obtain the existence of positive solutions of second-order three-point boundary value problem with dependence on the first-order derivative

$$
\begin{aligned}
& x^{\prime \prime}(t)+f\left(t, x(t), x^{\prime}(t)\right)=0, \quad 0<t<1, \\
& x(0)=0, \quad x(1)=\mu x(\eta),
\end{aligned}
$$
\end{abstract}

where $f:[0,1] \times[0, \infty) \times R \rightarrow[0, \infty)$ is a continuous function, $\mu>0, \eta \in(0,1), \mu \eta<1$. The interesting point is that the nonlinear term is dependent on the convection term.

MSC: $34 \mathrm{~B} 15 ; 34 \mathrm{~A} 08$

Keywords: Three-point boundary value problem; Fixed point theorem; Positive solution

\section{Introduction}

In recent years, there has been much attention focused on questions of solutions of twopoint, three-point, multi-point, and integral boundary value problems for nonlinear ordinary differential equations and fractional differential equations. For example, two-point boundary value problems $[3,15,29,39]$, beam equation problems $[5,13,16,36]$, boundary value problems at resonance $[2,6,42,43]$, fractional boundary value problems [8, 24], impulsive problems $[4,38]$, multi-point boundary value problems $[10,14,20,25,26,32$, $33,43]$, integral boundary value problems [7, 9, 17, 21, 22, 28, 37], $p$-Laplace problems $[11,13,24,27,30,31]$, delay problems [23, 34, 35], solitons [12], singular problems [3], Schrödinger problem $[40,41]$, etc.

Krasnosel'skii's fixed point theorem in a cone [18], the Leggett-Williams fixed point theorem [19], and five functional fixed point theorem [1] played an extremely important role in the research of the solvability of differential equation with boundary conditions.

However, most of the above works were done under the assumption that the first-order derivative is not involved explicitly in the nonlinear term [1-13, 16, 17, 20-30]. Krasnosel'skii's fixed point theorem in a cone [18] cannot concretely solve problems whose

(c) The Author(s) 2019. This article is distributed under the terms of the Creative Commons Attribution 4.0 International License (http://creativecommons.org/licenses/by/4.0/), which permits unrestricted use, distribution, and reproduction in any medium, provided you give appropriate credit to the original author(s) and the source, provide a link to the Creative Commons license, and indicate if changes were made. 
nonlinear terms involve the first-order derivative. In this paper, via a generalization of Krasnosel'skii's fixed point theorem in a cone [5] and some inequalities of the associated Green's function for the associated problem, the existence of positive solutions for the second-order three-point boundary value problem is studied

$$
\begin{aligned}
& x^{\prime \prime}(t)+f\left(t, x(t), x^{\prime}(t)\right)=0, \quad 0<t<1, \\
& x(0)=0, \quad x(1)=\mu x(\eta),
\end{aligned}
$$

where $f:[0,1] \times[0, \infty) \times R \rightarrow[0, \infty)$ is a continuous function, $\mu>0, \eta \in(0,1), \mu \eta<1$.

Readers may find that the concavity is crucial in giving some important estimates and in defining an appropriate cone, and the new fixed point theorem in a cone can be used to obtain positive solutions under more flexible conditions. Two examples are given to illustrate the main results.

\section{Preliminaries and lemmas}

In order to give the following lemma, let $X$ be a Banach space and $P$ be the cone in $X$. Assume that $\alpha, \beta: X \rightarrow R^{+}$are two continuous nonnegative functionals that satisfy

$$
\alpha(\lambda x) \leq|\lambda| \alpha(x), \quad \beta(\lambda x) \leq|\lambda| \beta(x) \quad \text { for } x \in X, \lambda \in[0,1],
$$

and

$$
M_{1} \max \{\alpha(x), \beta(x)\} \leq\|x\| \leq M_{2} \max \{\alpha(x), \beta(x)\} \quad \text { for } x \in X,
$$

where $M_{1}, M_{2}$ are two positive constants.

Lemma 2.1 ([5]) Let $r_{2}>r_{1}>0, L_{2}>L_{1}>0$ be constants and

$$
\Omega_{i}=\left\{x \in X \mid \alpha(x)<r_{i}, \beta(x)<L_{i}\right\}, \quad i=1,2,
$$

two open subsets in $X$ such that $\theta \in \Omega_{1} \subset \bar{\Omega}_{1} \subset \Omega_{2}$. In addition, let

$$
\begin{array}{ll}
C_{i}=\left\{x \in X \mid \alpha(x)=r_{i}, \beta(x) \leq L_{i}\right\}, & i=1,2 ; \\
D_{i}=\left\{x \in X \mid \alpha(x) \leq r_{i}, \beta(x)=L_{i}\right\}, & i=1,2 .
\end{array}
$$

Assume that $T: P \rightarrow P$ is a completely continuous operator satisfying

$\left(S_{1}\right) \alpha(T x) \leq r_{1}, x \in C_{1} \cap P ; \beta(T x) \leq L_{1}, x \in D_{1} \cap P ; \alpha(T x) \geq r_{2}, x \in C_{2} \cap P ; \beta(T x) \geq L_{2}$, $x \in D_{2} \cap P$;

or

$\left(S_{2}\right) \alpha(T x) \geq r_{1}, x \in C_{1} \cap P ; \beta(T x) \geq L_{1}, x \in D_{1} \cap P ; \alpha(T x) \leq r_{2}, x \in C_{2} \cap P ; \beta(T x) \leq L_{2}$, $x \in D_{2} \cap P$;

then $T$ has at least one fixed point in $\left(\bar{\Omega}_{2} \backslash \Omega_{1}\right) \cap P$. 
Lemma 2.2 Let $0<\mu<\frac{1}{\eta}, \eta \in(0,1)$. The Green's function of the following boundary value problem:

$$
\begin{array}{ll}
-x^{\prime \prime}(t)=0, & 0<t<1, \\
x(0)=0, & x(1)=\mu x(\eta),
\end{array}
$$

is given by

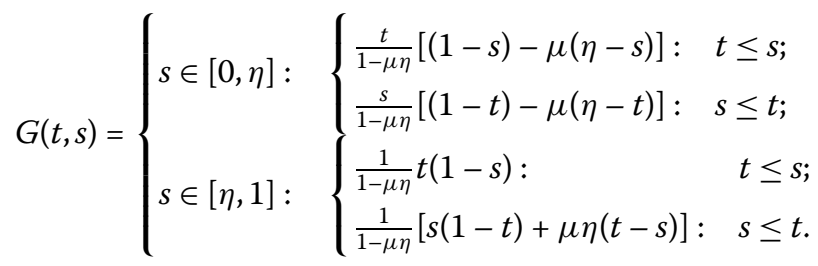

Moreover, for each $0<s<1$,

$$
G(t, s) \geq \gamma \max _{0 \leq t \leq 1} G(t, s), \quad \eta \leq t \leq 1,
$$

where $\gamma=\min \left\{\mu \eta, \frac{\mu(1-\eta)}{(1-\mu \eta)}, \eta\right\}$

Proof The detailed formula of Green's function $G(t, s)$ was given in [14]. In the following proof, we focus on the existence of $\gamma$. It is clear that $G(t, s) \geq 0$ for $t \in[\eta, 1], s \in[0,1]$. Consider the relation of $\mu$ and $\eta$, we divide the range of $\mu$ into two cases.

Case 1: $0<\mu \leq 1$. With the definition of $G(t, s)$, there are

$$
\min _{t \in[\eta, 1]} G(t, s)= \begin{cases}\frac{s \mu(1-\eta)}{1-\mu \eta}, & s \in[0, \eta] ; \\ \frac{\eta \mu(1-s)}{1-\mu \eta}, & s \in[\eta, 1],\end{cases}
$$

and

$$
\max _{t \in[0,1]} G(t, s)= \begin{cases}\frac{s}{1-\mu \eta}[(1-s)-\mu(\eta-s)], & s \in[0, \eta] ; \\ \frac{s(1-s)}{1-\mu \eta}, & s \in[\eta, 1] .\end{cases}
$$

Here we set $\gamma=\min \left\{\mu \eta, \frac{\mu(1-\eta)}{1-\mu \eta}\right\}$, and then it satisfies

$$
G(t, s) \geq \gamma \max _{t \in[0,1]} G(t, s) \quad \text { for } t \in[\eta, 1], s \in[0,1] .
$$

Case 2: $1<\mu<1 / \eta$. With the definition of $G(t, s)$, there are

$$
\min _{t \in[\eta, 1]} G(t, s)= \begin{cases}\frac{s(1-\eta)}{1-\mu \eta}, & s \in[0, \eta] \\ \frac{\eta(1-s)}{1-\mu \eta}, & s \in[\eta, 1]\end{cases}
$$

and

$$
\max _{t \in[0,1]} G(t, s)= \begin{cases}\frac{s \mu(1-\eta)}{1-\mu \eta}, & s \in[0, \eta] \\ \frac{s(1-s)}{1-\mu \eta} \max \{s, \mu \eta\}, & s \in[\eta, 1] .\end{cases}
$$


Set $\gamma=\min \left\{\eta, \frac{1}{\mu}\right\}=\eta$, then

$$
G(t, s) \geq \gamma \max _{t \in[0,1]} G(t, s), \quad \text { for } t \in[\eta, 1], s \in[0,1]
$$

The proof is complete.

\section{Existence results of positive solutions}

In this section, by using Lemma 2.1 and Lemma 2.2, we obtain positive solutions of (1.1), (1.2).

If $x=x(t)$ satisfies the operator equation

$$
x(t)=(T x)(t):=\int_{0}^{1} G(t, s) f\left(s, x(s), x^{\prime}(s)\right) d s, \quad 0 \leq t \leq 1
$$

where $G(t, s) \geq 0$ is Green's function for boundary value problem (2.3), (2.4), then $x=x(t)$ is the solution of problem (1.1), (1.2).

Let $X$ be a Banach space in $C^{1}[0,1]$, with

$$
\|x\|=\max \left\{\max _{0 \leq t \leq 1}|x(t)|, \max _{0 \leq t \leq 1}\left|x^{\prime}(t)\right|\right\}
$$

Define a cone $P$ by

$$
P=\left\{x \in X \mid x(t) \geq 0, \text { and } \min _{\eta \leq t \leq 1} x(t) \geq \gamma \max _{0 \leq t \leq 1}|x(t)|\right\}
$$

and functionals

$$
\alpha(x)=\max _{0 \leq t \leq 1}|x(t)|, \quad \beta(x)=\max _{0 \leq t \leq 1}\left|x^{\prime}(t)\right| \quad \text { for } x \in X
$$

By (2.1), (2.2), $\alpha, \beta: X \rightarrow R^{+}$are two continuous nonnegative functionals such that $\|x\|=$ $\max \{\alpha(x), \beta(x)\}$ and

$$
P=\left\{x \in X \mid x(t) \geq 0 \text {, and } \min _{\eta \leq t \leq 1} x(t) \geq \gamma \alpha(x)\right\} .
$$

Denote

$$
\begin{aligned}
M= & \max _{0 \leq t \leq 1} \int_{0}^{1} G(t, s) d s, \quad N=\max _{0 \leq t \leq 1} \int_{\eta}^{1} G(t, s) d s \\
A= & \int_{\eta}^{1}(1-s) d s+\int_{0}^{\eta}(1-s-\mu \eta+\mu s) d s, \\
\bar{A}= & \int_{\eta}^{1-h}(1-s) d s+\int_{h}^{\eta}(1-s-\mu \eta+\mu s) d s, \\
B= & \frac{1}{1-\mu \eta} \max \left\{\int_{\eta}^{1}(1-s) d s+\int_{0}^{\eta}(1-s-\mu \eta+\mu s) d s,\right. \\
& \left.\int_{\eta}^{1}|\mu \eta-s| d s+\int_{0}^{\eta} s|\mu-1| d s\right\} .
\end{aligned}
$$


$T: P \rightarrow P$ is completely continuous, and the following is a simple proof of that. In fact, if $x \in P$, there is

$$
\begin{aligned}
(T x)(t) & =\int_{0}^{1} G(t, s) f\left(s, x(s), x^{\prime}(s)\right) d s \\
& \leq \int_{0}^{1} \max _{0 \leq t \leq 1} G(t, s) \cdot f\left(s, x(s), x^{\prime}(s)\right) d s,
\end{aligned}
$$

so that

$$
\alpha(T x)=\max _{0 \leq t \leq 1}(T x)(t) \leq \int_{0}^{1} \max _{0 \leq t \leq 1} G(t, s) \cdot f\left(s, x(s), x^{\prime}(s)\right) d s .
$$

Combining this with (2.6), we get

$$
\begin{aligned}
\min _{\eta \leq t \leq 1}(T x)(t) & =\min _{\eta \leq t \leq 1} \int_{0}^{1} G(t, s) f\left(s, x(s), x^{\prime}(s)\right) d s \\
& \geq \gamma \int_{0}^{1} \max _{0 \leq t \leq 1} G(t, s) \cdot f\left(s, x(s), x^{\prime}(s)\right) d s \\
& \geq \gamma \cdot \alpha(T x) .
\end{aligned}
$$

Moreover, from the positivity of $G(t, s)$, there is $(T x)(t) \geq 0,0 \leq t \leq 1$, for $x \in P$. So we can get $T: P \rightarrow P$. Further, standard arguments yield that $T$ is completely continuous.

Theorem 3.1 Suppose that there are four constants $r_{2}>r_{1}>0, L_{2}>L_{1}>0$ such that $\max \left\{\frac{r_{1}}{M}, \frac{L_{1}}{A}\right\} \leq \min \left\{\frac{r_{2}}{M}, \frac{L_{2}}{B}\right\}$ and the following assumptions hold:

$\left(A_{1}\right) f(t, u, v) \geq \max \left\{\frac{r_{1}}{M}, \frac{L_{1}}{A}\right\}$ for $(t, u, v) \in[0,1] \times\left[0, r_{1}\right] \times\left[-L_{1}, L_{1}\right]$;

$\left(A_{2}\right) f(t, u, v) \leq \min \left\{\frac{r_{2}}{M}, \frac{L_{2}}{B}\right\}$ for $(t, u, v) \in[0,1] \times\left[0, r_{2}\right] \times\left[-L_{2}, L_{2}\right]$.

Then problem (1.1), (1.2) has at least one positive solution $x(t)$ such that

$$
r_{1} \leq \max _{0 \leq t \leq 1} x(t) \leq r_{2} \quad \text { or } \quad L_{1} \leq \max _{0 \leq t \leq 1}\left|x^{\prime}(t)\right| \leq L_{2}
$$

Proof Take two bounded open subsets in $X$

$$
\Omega_{i}=\left\{x \in X \mid \alpha(x)<r_{i}, \beta(x)<L_{i}\right\}, \quad i=1,2 .
$$

In addition, let

$$
\begin{array}{ll}
C_{i}=\left\{x \in X \mid \alpha(x)=r_{i}, \beta(x) \leq L_{i}\right\}, & i=1,2 ; \\
D_{i}=\left\{x \in X \mid \alpha(x) \leq r_{i}, \beta(x)=L_{i}\right\}, & i=1,2 .
\end{array}
$$

For $x \in C_{1} \cap P$, by $\left(A_{1}\right)$, there is

$$
\begin{aligned}
\alpha(T x) & =\max _{t \in[0,1]}\left|\int_{0}^{1} G(t, s) f\left(s, x(s), x^{\prime}(s)\right) d s\right| \\
& \geq \frac{r_{1}}{M} \cdot \max _{t \in[0,1]}\left|\int_{0}^{1} G(t, s) d s\right|=r_{1} .
\end{aligned}
$$


Taking into account the continuity and properties of $T$, we have

$$
\begin{aligned}
(T x)^{\prime}(t)= & -\int_{0}^{t} f\left(s, x(s), x^{\prime}(s)\right) d s+\frac{1}{1-\mu \eta} \int_{0}^{1}(1-s) f\left(s, x(s), x^{\prime}(s)\right) d s \\
& -\frac{\mu}{1-\mu \eta} \int_{0}^{\eta}(\eta-s) f\left(s, x(s), x^{\prime}(s)\right) d s \\
(T x)^{\prime \prime}(t)= & -f\left(t, x(t), x^{\prime}(t)\right) \leq 0, \quad 0 \leq t \leq 1
\end{aligned}
$$

Thus, $(T x)(t)$ is concave on $[0,1]$ and

$$
\max _{t \in[0,1]}\left|(T x)^{\prime}(t)\right|=\max \left\{\left|(T x)^{\prime}(0)\right|,\left|(T x)^{\prime}(1)\right|\right\}
$$

For $x \in D_{1} \cap P$, combine $\left(A_{1}\right)$ and $f \geq 0$, there is

$$
\begin{aligned}
\beta(T x)= & \max _{t \in[0,1]}\left|(T x)^{\prime}(t)\right| \\
= & \max \left\{\left|(T x)^{\prime}(0)\right|,\left|(T x)^{\prime}(1)\right|\right\} \\
\geq & \left|(T x)^{\prime}(0)\right| \\
= & \frac{1}{1-\mu \eta}\left[\int_{\eta}^{1}(1-s) f\left(s, x(s), x^{\prime}(s)\right) d s\right. \\
& \left.+\int_{0}^{\eta}(1-s-\mu \eta+\mu s) f\left(s, x(s), x^{\prime}(s)\right) d s\right] \\
\geq & \frac{L_{1}}{A} \cdot\left[\int_{\eta}^{1}(1-s) d s+\int_{0}^{\eta}(1-s-\mu \eta+\mu s) d s\right] \\
= & \frac{L_{1}}{A} \cdot A=L_{1} .
\end{aligned}
$$

For $x \in C_{2} \cap P$, by $\left(A_{2}\right)$, there is

$$
\begin{aligned}
\alpha(T x) & =\max _{t \in[0,1]}\left|\int_{0}^{1} G(t, s) f\left(s, x(s), x^{\prime}(s)\right) d s\right| \\
& \leq \max _{t \in[0,1]} \int_{0}^{1} G(t, s) \cdot \frac{r_{2}}{M} d s \\
& =\frac{r_{2}}{M} \cdot \max _{t \in[0,1]} \int_{0}^{1} G(t, s) d s=r_{2} .
\end{aligned}
$$

For $x \in D_{2} \cap P$, by $\left(A_{2}\right)$, there is

$$
\begin{aligned}
\beta(T x)= & \max _{t \in[0,1]}\left|(T x)^{\prime}(t)\right| \\
= & \max \left\{\left|(T x)^{\prime}(0)\right|,\left|(T x)^{\prime}(1)\right|\right\} \\
\leq & \frac{1}{1-\mu \eta} \max \left\{\int_{\eta}^{1}(1-s) f\left(s, x(s), x^{\prime}(s)\right) d s\right. \\
& +\int_{0}^{\eta}(1-s-\mu \eta+\mu s) f\left(s, x(s), x^{\prime}(s)\right) d s,
\end{aligned}
$$




$$
\begin{aligned}
& \left.\int_{\eta}^{1}|\mu \eta-s| f\left(s, x(s), x^{\prime}(s)\right) d s+\int_{0}^{\eta} s|\mu-1| f\left(s, x(s), x^{\prime}(s)\right) d s\right\} \\
\leq & \frac{L_{2}}{B} \cdot B=L_{2} .
\end{aligned}
$$

Now, from Lemma 2.1 we can get that there is $x \in\left(\bar{\Omega}_{2} \backslash \Omega_{1}\right) \cap P$ such that $x=T x$. The above proof satisfies the condition of Lemma 2.1, so problem (1.1), (1.2) has at least one positive solution $x(t)$ such that

$$
r_{1} \leq \alpha(x) \leq r_{2} \quad \text { or } \quad L_{1} \leq \beta(x) \leq L_{2}
$$

i.e.,

$$
r_{1} \leq \max _{0 \leq t \leq 1} x(t) \leq r_{2} \quad \text { or } \quad L_{1} \leq \max _{0 \leq t \leq 1}\left|x^{\prime}(t)\right| \leq L_{2}
$$

The proof is complete.

Theorem 3.2 Suppose that there are five constants $0<r_{1}<r_{2}, 0<L_{1}<L_{2}, 0 \leq h \leq$ $\min \{\eta, 1-\eta\}$ such that $\max \left\{\frac{r_{1}}{N}, \frac{L_{1}}{\bar{A}}\right\} \leq \min \left\{\frac{r_{2}}{M}, \frac{L_{2}}{B}\right\}$ and the following assumptions hold:

$\left(A_{3}\right) f(t, u, v) \geq \frac{r_{1}}{N}$ for $(t, u, v) \in[\eta, 1] \times\left[\gamma r_{1}, r_{1}\right] \times\left[-L_{1}, L_{1}\right]$;

$\left(A_{4}\right) f(t, u, v) \geq \frac{L_{1}}{\bar{A}}$ for $(t, u, v) \in[h, 1-h] \times\left[0, r_{1}\right] \times\left[-L_{1}, L_{1}\right]$;

$\left(A_{5}\right) f(t, u, v) \leq \min \left\{\frac{r_{2}}{M}, \frac{L_{2}}{B}\right\}$ for $(t, u, v) \in[0,1] \times\left[0, r_{2}\right] \times\left[-L_{2}, L_{2}\right]$.

Then problem (1.1), (1.2) has at least one positive solution $x(t)$ such that

$$
r_{1} \leq \max _{0 \leq t \leq 1} x(t) \leq r_{2} \quad \text { or } \quad L_{1} \leq \max _{0 \leq t \leq 1}\left|x^{\prime}(t)\right| \leq L_{2} .
$$

Proof We just need to notice the difference between the following proof and the proof of Theorem 3.1.

For $x \in C_{1} \cap P$, by the definition of $P$, there is

$$
x(t) \geq \gamma \alpha(x)=\gamma r_{1}, \quad \text { for } t \in[\eta, 1] .
$$

By $\left(A_{3}\right)$, there is

$$
\begin{aligned}
\alpha(T x) & =\max _{t \in[0,1]}\left|\int_{0}^{1} G(t, s) f\left(s, x(s), x^{\prime}(s)\right) d s\right| \\
& \geq \max _{t \in[0,1]}\left|\int_{\eta}^{1} G(t, s) f\left(s, x(s), x^{\prime}(s)\right) d s\right| \\
& \geq \max _{t \in[0,1]}\left|\int_{\eta}^{1} G(t, s) \cdot \frac{r_{1}}{N} d s\right| \\
& =\frac{r_{1}}{N} \cdot \max _{t \in[0,1]}\left|\int_{\eta}^{1} G(t, s) d s\right|=r_{1} .
\end{aligned}
$$

For $x \in D_{1} \cap P$, by $\left(A_{4}\right)$, there is

$$
\begin{aligned}
\beta(T x) & =\max _{t \in[0,1]}\left|(T x)^{\prime}(t)\right| \\
& =\max \left\{\left|(T x)^{\prime}(0)\right|,\left|(T x)^{\prime}(1)\right|\right\}
\end{aligned}
$$




$$
\begin{aligned}
\geq & \left|(T x)^{\prime}(0)\right| \\
= & \frac{1}{1-\mu \eta}\left[\int_{\eta}^{1}(1-s) f\left(s, x(s), x^{\prime}(s)\right) d s\right. \\
& \left.+\int_{0}^{\eta}(1-s-\mu \eta+\mu s) f\left(s, x(s), x^{\prime}(s)\right) d s\right] \\
\geq & \frac{1}{1-\mu \eta}\left[\int_{\eta}^{1-h}(1-s) f\left(s, x(s), x^{\prime}(s)\right) d s\right. \\
& \left.+\int_{h}^{\eta}(1-s-\mu \eta+\mu s) f\left(s, x(s), x^{\prime}(s)\right) d s\right] \\
\geq & \frac{L_{1}}{\bar{A}} \cdot\left[\int_{\eta}^{1-h}(1-s) d s+\int_{h}^{\eta}(1-s-\mu \eta+\mu s) d s\right] \\
= & \frac{L_{1}}{\bar{A}} \cdot \bar{A}=L_{1} .
\end{aligned}
$$

The rest of the proof is similar to that of Theorem 3.1 and is omitted.

Remark 3.1 The conditions of our results are weaker than those of [14].

\section{Examples}

We present some examples to illustrate the main results.

Example 4.1 Consider the boundary value problem

$$
\begin{aligned}
& x^{\prime \prime}(t)+f\left(t, x(t), x^{\prime}(t)\right)=0, \quad 0<t<1, \\
& x(0)=0, \quad x(1)=x\left(\frac{1}{2}\right),
\end{aligned}
$$

where

$$
f(t, u, v)=\frac{u^{2}(\sin t)^{2}}{16}+\frac{v \cos t}{32}+\frac{65}{64}
$$

Direct computation shows that

$$
M=\frac{7}{8}, \quad N=2, \quad A=\frac{3}{8}, \quad B=\frac{3}{4} .
$$

Choose

$$
r_{1}=\frac{1}{2}, \quad r_{2}=1, \quad L_{1}=\frac{1}{4}, \quad L_{2}=1,
$$

then $\max \left\{\frac{r_{1}}{M}, \frac{L_{1}}{A}\right\}=\frac{2}{3} \leq \min \left\{\frac{r_{2}}{M}, \frac{L_{2}}{B}\right\}=\frac{8}{7}$, and

$$
\begin{aligned}
& f(t, u, v) \geq \frac{169}{128} \geq \max \left\{\frac{r_{1}}{M}, \frac{L_{1}}{A}\right\}=\frac{2}{3}, \quad(t, u, v) \in[0,1] \times\left[0, \frac{1}{2}\right] \times\left[\frac{-1}{4}, \frac{1}{4}\right], \\
& f(t, u, v) \leq \frac{71}{64} \leq \min \left\{\frac{r_{2}}{M}, \frac{L_{2}}{B}\right\}=\frac{8}{7}, \quad(t, u, v) \in[0,1] \times[0,1] \times[-1,1] .
\end{aligned}
$$


That is to say, all the assumptions of Theorem 3.1 are satisfied, then problem (4.1), (4.2) has at least one positive solution $x$ such that

$$
\frac{1}{2} \leq \max _{0 \leq t \leq 1} x(t) \leq 1, \quad \text { or } \quad \frac{1}{4} \leq \max _{0 \leq t \leq 1}\left|x^{\prime}(t)\right| \leq 1 .
$$

Example 4.2 Consider the boundary value problem

$$
\begin{aligned}
& x^{\prime \prime}(t)+f\left(t, x(t), x^{\prime}(t)\right)=0, \quad 0<t<1, \\
& x(0)=0, \quad x(1)=x\left(\frac{1}{3}\right),
\end{aligned}
$$

where

$$
f(t, u, v)=\left(\frac{t}{5}+2\right)\left(\frac{1}{u+1}-\frac{v^{2}}{6}\right) .
$$

Direct computation shows

$$
M=\frac{8}{9}, \quad N=\frac{1}{2}, \quad \bar{A}=\frac{4}{9}, \quad B=\frac{2}{3}, \quad \gamma=\frac{1}{3} .
$$

Choose

$$
r_{1}=\frac{1}{2}, \quad r_{2}=2, \quad L_{1}=\frac{1}{2}, \quad L_{2}=2, \quad h=\frac{1}{3},
$$

then $\max \left\{\frac{r_{1}}{M}, \frac{L_{1}}{A}\right\}=\frac{9}{8} \leq \min \left\{\frac{r_{2}}{M}, \frac{L_{2}}{B}\right\}=\frac{9}{4}$, and

$$
\begin{aligned}
& f(t, u, v) \geq \frac{31}{24} \approx 1.29 \geq \frac{r_{1}}{N}=1, \quad(t, u, v) \in\left[\frac{1}{3}, 1\right] \times\left[\frac{1}{6}, \frac{1}{2}\right] \times\left[-\frac{1}{2}, \frac{1}{2}\right], \\
& f(t, u, v) \geq 1.29 \geq \frac{L_{1}}{A}=\frac{9}{8} \approx 1.125, \quad(t, u, v) \in\left[\frac{1}{3}, \frac{2}{3}\right] \times\left[0, \frac{1}{2}\right] \times\left[-\frac{1}{2}, \frac{1}{2}\right], \\
& f(t, u, v) \leq 2.2 \leq \min \left\{\frac{r_{2}}{M}, \frac{L_{2}}{B}\right\}=2.25, \quad(t, u, v) \in[0,1] \times[0,2] \times[-2,2],
\end{aligned}
$$

i.e., all the assumptions of Theorem 3.2 are satisfied, then problem (4.3), (4.4) has at least one positive solution $x$ such that

$$
\frac{1}{2} \leq \max _{0 \leq t \leq 1} x(t) \leq 2, \quad \text { or } \quad \frac{1}{2} \leq \max _{0 \leq t \leq 1}\left|x^{\prime}(t)\right| \leq 2 .
$$

\section{Conclusion}

By the use of a fixed point theorem, some existence results for a class of second-order differential equations with three-point boundary value conditions are obtained. The interesting point is that the nonlinear term is dependent on the convection term. 
Availability of data and materials

Data sharing not applicable to this article as no data sets were generated or analysed during the current study.

\section{Ethics approval and consent to participate}

Not applicable.

\section{Competing interests}

The authors declare that they have no competing interests.

\section{Consent for publication}

All authors agree to publication of this paper in JIAP.

\section{Authors' contributions}

All authors contributed equally to the writing of this paper. All authors read and approved the final manuscript.

\section{Publisher's Note}

Springer Nature remains neutral with regard to jurisdictional claims in published maps and institutional affiliations.

\section{Received: 19 January 2019 Accepted: 18 March 2019 Published online: 21 March 2019}

\section{References}

1. Avery, R.: A generalization of the Leggett-Williams fixed point theorem. Math. Sci. Res. Hot-Line 2, 9-14 (1998)

2. Bai, Z:: Solvability for a class of fractional $m$-point boundary value problem at resonance. Comput. Math. Appl. 62 , 1292-1302 (2011)

3. Bai, Z., Chen, Y., Lian, H., Sun, S.: On the existence of blow up solutions for a class of fractional differential equations. Fract. Calc. Appl. Anal. 17(4), 1175-1187 (2014)

4. Bai, Z., Dong, X., Yin, C.: Existence results for impulsive nonlinear fractional differential equation with mixed boundary conditions. Bound. Value Probl. 2016, 63 (2016)

5. Bai, Z., Ge, W.: Existence of positive solutions to fourth-order quasilinear boundary value problems. Acta Math. Sin. 22, 1825-1830 (2006)

6. Bai, Z., Zhang, Y.: Solvability of fractional three-point boundary value problems with nonlinear growth. Appl. Math. Comput. 218(5), 1719-1725 (2011)

7. Cabada, A., Wang, G.: Positive solutions of nonlinear fractional differential equations with integral boundary value conditions. Abstr. Appl. Anal. 2012, 403 (2012)

8. Cui, Y.: Uniqueness of solution for boundary value problems for fractional differential equations. Appl. Math. Lett. 51, 48-54 (2016)

9. Cui, Y., Ma, W., Wang, X., Su, X.: Uniqueness theorem of differential system with coupled integral boundary conditions. Electron. J. Qual. Theory Differ. Equ. 2018, 9, 1-10 (2018)

10. Cui, Y., Sun, J.: Positive solutions for second-order three-point boundary value problems in Banach spaces. Acta Math $\operatorname{Sin} .4,743-751(2011)$

11. Cui, Y., Sun, J.: A generalization of Mahadevan's version of the Krein-Rutman theorem and applications to $p$-Laplacian boundary value problems. Abstr. Appl. Anal. 2012, 1 (2012)

12. Dong, H., Guo, B., Yin, B.: Generalized fractional supertrace identity for Hamiltonian structure of NLS-MKdV hierarchy with self-consistent sources. Anal. Math. Phys. 6, 199-209 (2016)

13. Feng, M., Li, P., Sun, S.: Symmetric positive solutions for fourth-order $n$-dimensional $m$-Laplace system. Bound. Value Probl. 2018, 63 (2018)

14. Guo, Y., Ge, W.: Positive solutions for three-point boundary value problems with dependence on the first order derivative. J. Math. Anal. Appl. 290, 291-301 (2004)

15. He, L., Dong, X., Bai, Z., Chen, B.: Solvability of some two-point fractional boundary value problems under barrier strip conditions. J. Funct. Spaces 2017, Article ID 1465623 (2017)

16. Ji, D., Bai, Z., Ge, W.: The existence of countably many positive solutions for singular multipoint boundary value problems. Nonlinear Anal., Theory Methods Appl. 72, 955-964 (2010)

17. Jia, M., Wang, P.: Multiple positive solutions for integro-differential equations with integral boundary conditions and sign changing nonlinearities. Electron. J. Differ. Equ. 2012, 31 (2012)

18. Krasnosel'skii, M.: Positive Solutions of Operator Equations. Noordhoff, Gronignen (1964)

19. Leggett, R., Williams, L.: Multiple positive fixed points of nonlinear operators on ordered Banach spaces. Indiana Univ. Math. J. 28, 673-688 (1979)

20. Li, H.: Existence of nontrivial solutions for superlinear three-point boundary value problems. Acta Math. Appl. Sin. Engl. Ser. 33, 1043-1052 (2017)

21. Li, H., Sun, F.: Existence of solutions for integral boundary value problems of second-order ordinary differentia equations. Bound. Value Probl. 2012, 1 (2012)

22. Li, H., Sun, J.: Positive solutions of superlinear semipositone nonlinear boundary value problems. Comput. Math. Appl. 61, 2806-2815 (2011)

23. Li, H., Zhu, Y., Liu, J., Wang, Y.: Consensus of second-order delayed nonlinear multi-agent systems via node-based distributed adaptive completely intermittent protocols. Appl. Math. Comput. 326, 1-15 (2018)

24. Liu, X., Jia, M.: The positive solutions for integral boundary value problem of fractional $p$-Laplacian equation with mixed derivatives. Mediterr. J. Math. 14, 94 (2017)

25. Ma, R.: Positive solutions of nonlinear three-point boundary value problem. Electron. J. Differ. Equ. 1999, 34, 1-8 (1999)

26. Ntouyas, S.K., Pourhadi, E.: Positive solutions of nonlinear fractional three-point boundary-value problem. Matematiche 73(1), 139-154 (2018) 
27. Sheng, K., Zhang, W., Bai, Z:: Positive solutions to fractional boundary value problems with $p$-Laplacian on time scales. Bound. Value Probl. 2018, 70 (2018)

28. Song, Q., Bai, Z.: Positive solutions of fractional differential equations involving the Riemann-Stieltjes integral boundary condition. Adv. Differ. Equ. 2018, 183 (2018)

29. Song, Q., Dong, X., Bai, Z., Chen, B.: Existence for fractional Dirichlet boundary value problem under barrier strip conditions. J. Nonlinear Sci. Appl. 10, 3592-3598 (2017)

30. Tian, Y., Sun, S., Bai, Z.: Positive solutions of fractional differential equations with p-Laplacian. J. Funct. Spaces 2017, Article ID 3187492 (2017)

31. Tian, Y., Wei, Y., Sun, S.: Multiplicity for fractional differential equations with $p$-Laplacian. Bound. Value Probl. 2018, 127 (2018)

32. Wang, G., Ntouyas, S.K., Zhang, L.: Positive solutions of the three-point boundary value problem for fractional-order differential equations with an advanced argument. Adv. Differ. Equ. 2011, 2 (2011)

33. Wang, G., Zhang, L., Ntouyas, S.K.: Multiplicity of positive solutions for fractional order three-point boundary value problems. Commun. Appl. Nonlinear Anal. 20, 41-53 (2013)

34. Wang, Z.: A numerical method for delayed fractional-order differential equations. J. Appl. Math. 2013, Article ID 256071 (2013)

35. Wang, Z., Huang, X., Shi, G.: Analysis of nonlinear dynamics and chaos in a fractional order financial system with time delay. Comput. Math. Appl. 62, 1531-1539 (2011)

36. Wei, Y., Song, Q., Bai, Z.: Existence and iterative method for some fourth order nonlinear boundary value problems, Appl. Math. Lett. 87, 101-107 (2019)

37. Zhang, J., Zhang, G., Li, H.: Positive solutions of second-order problem with dependence on derivative in nonlinearity under Stieltjes integral boundary condition. Electron. J. Qual. Theory Differ. Equ. 2018, 4, 1-13 (2018)

38. Zhang, T., Meng, X., Song, Y., Zhang, T.: A stage-structured predator-prey SI model with disease in the prey and impulsive effects. Math. Model. Anal. 18, 505-528 (2013)

39. Zhang, W., Bai, Z., Sun, S.: Extremal solutions for some periodic fractional differential equations. Adv. Differ. Equ. 2016, 179 (2016)

40. Zhang, X., Liu, L., Wu, Y., Cui, Y.: The existence and nonexistence of entire large solutions for a quasilinear Schrödinger elliptic system by dual approach. J. Math. Anal. Appl. 464, 1089-1106 (2018)

41. Zhang, X., Wu, Y., Cui, Y.: Existence and nonexistence of blow-up solutions for a Schrödinger equation involving a nonlinear operator. Appl. Math. Lett. 82, 85-91 (2018)

42. Zhang, Y.: Existence results for a coupled system of nonlinear fractional multi-point boundary value problems at resonance. J. Inequal. Appl. 2018, 198 (2018)

43. Zou, Y., Liu, L., Cui, Y.: The existence of solutions for four-point coupled boundary value problems of fractional differential equations at resonance. Abstr. Appl. Anal. 2014, 1 (2014)

\section{Submit your manuscript to a SpringerOpen ${ }^{\circ}$ journal and benefit from:}

- Convenient online submission

- Rigorous peer review

- Open access: articles freely available online

- High visibility within the field

- Retaining the copyright to your article

Submit your next manuscript at $\gg$ springeropen.com 